\title{
Editorial: Spatial Tools for Integrated and Inclusive Landscape Governance
}

\author{
Mirjam A. F. Ros-Tonen $\mathbb{1}^{1} \cdot$ Louise Willemen ${ }^{2}$
}

Received: 28 September 2021 / Accepted: 28 September 2021 / Published online: 26 October 2021

(c) The Author(s), under exclusive licence to Springer Science+Business Media, LLC, part of Springer Nature 2021

Climate and environmental challenges in the Anthropocene adversely affect the ecological integrity of mosaic landscapes, jeopardizing food security, livelihoods, climate resilience, and the provision of ecosystem services. Similarly, there are concerns about persistent poverty, inequality, and the exclusion of marginalized people from land use and decision-making. Hence, the growing call to deal with these social and environmental issues holistically at the landscape level through inclusive multi-stakeholder approaches.

This special issue on Spatial tools for integrated and inclusive landscape governance is a follow-up to Environmental Management 62(1), titled 'From Synergy to Complexity: The Trend Toward Integrated Value Chain and Landscape Governance' (Ros-Tonen et al. 2018). This time, we focus specifically on spatial tools used to enhance multistakeholder engagement in integrated landscape governance to achieve greater inclusivity. With spatial tools, we mean mapping, 3D modeling, and place-based scenario-building processes employed to achieve governance or management objectives (McCall and Dunn 2012; Willemen et al. 2014). Participatory (geo)spatial tools such as participatory geographical systems (PGIS) and participatory mapping specifically aim to enhance stakeholder engagement and collaboration on spatial questions while empowering the least powerful among them by uncovering their views and claims (Ros-Tonen et al. 2021, this issue). The paper by Ros-Tonen et al. situates the use of participatory spatial tools in debates on integrated landscape governance and inclusive development. In doing so, the authors add some

Mirjam A. F. Ros-Tonen

m.a.f.ros-tonen@uva.nl

1 Department of Geography, Planning and International Development Studies, University of Amsterdam, Amsterdam, The Netherlands

2 Faculty of Geo-Information Science and Earth Observation (ITC), University of Twente, Enschede, The Netherlands critical notes and warnings regarding the inclusivity, representativity, ethics, and safety in using these tools. The forum paper highlights the drivers that caused the growing use of participatory spatial tools in landscape governance and argues that further research is needed to broaden the scope of applying the tools, strengthen inclusivity in the processes, and develop new technologies to improve their applicability in landscape governance.

Illustrative for holistic landscape approaches are forest landscape restoration (FLR) projects. Djenontin et al. (2021, this issue) present a categorization of such projects, which they apply to five FLR projects in sub-Saharan Africa. They show how FLR projects aim to reconstruct degraded nature into multifunctional landscapes for the continued provision of sustainable livelihoods, biodiversity conservation, and ecosystem services while offering guidance for the design of future FLR projects. None of the reviewed projects applied spatial tools in the identification, implementation, or evaluation stage, which the authors signal a missed opportunity to engage actors in restoration efforts.

The remaining papers examine the use of participatory or participatorily used spatial tools ${ }^{1}$ in various contexts. Four papers show how scenario development, combined with participatory mapping and other spatial tools, can be used for multi-stakeholder negotiation on common concerns, desired future landscapes, and actions needed to achieve those. Shantiko et al. (2021, this issue) do so to engage local stakeholders in land-use planning in Indonesia. Their participatory prospective analysis (PPA) helps stakeholders

\footnotetext{
${ }^{1}$ In constrast to participatory spatial tools, participatorily used spatial tools are not participatory by design, but (partly) used as such. An example is the LUMENS framework applied by Do et al. (2021, this issue), which combines GIS-based land-use mapping and carbon-stock assessment with participatory baseline establishment and participatory backcasting. Another example is the use of boosted spatial regression trees (Meyer et al., 2021, this issue) combined with participatorily developed indicators for land-use monitoring.
} 
understand landscape dynamics better. The authors claim that applying their method represents a transformative change in how local stakeholders are usually approached. Do et al. (2021, this issue) present the comprehensive LUMENS framework, short for participatory land-use planning for multiple ecosystem services. Based on its implementation in northwest Vietnam, they show how this framework creates a platform for multi-stakeholder negotiation on land-use planning and argue that this is key to achieving emission reduction and climate change mitigation. Best et al. (2021, this issue) pilot a combination of scenario building with other spatial tools (3D modeling and a 'serious game' to visualize trade-offs) for complementary insights into stakeholder interests in Suriname. Asubonteng et al. (2021, this issue) applied their participatory spatial backcasting tool in a mixed cocoa-oil palm landscape in Ghana's Eastern Region as a contribution to operationalizing landscape approaches.

With the ensuing papers by Aggrey et al. (2021, this issue) and Somuah et al. (2021, this issue), we remain in Ghana. Both papers report how participatory mapping helps uncover how rural landscape dwellers perceive the dynamics in a landscape marked by competing land uses. The paper by Aggrey et al. shows participatory maps that reveal how mining and the associated growth of settlements puts pressure on land for food crops. Somuah et al. zoom in on the threats to strictly protected forest reserves and argue that participatory mapping brings drivers of deforestation and forest degradation to the fore that remain uncovered in official reports. Both papers emphasize the importance of participatory mapping for inclusive landscape governance and highlight ethical and other fundamental conditions that should be met when applied.

Meyer et al. (2021, this issue) shift the focus to a periurban setting in the Global North. They present an indicator-based monitoring system for land consumption for settlement development that allows German municipalities to holistically approach landscape governance. In the next section, we synthesize the collective lessons from the papers in this special issue.

\section{Potentials and Limitations of Using Spatial Tools for Integrated and Inclusive Landscape Governance}

Table 1 provides an overview of the scope of the studies, the spatial tools used, and the potentials and limitations reported by the authors. The overview shows that participatory scenario building — notably backcasting - is a popular spatial tool to engage stakeholders in deliberations on current and anticipated landscape dynamics and pathways toward a desirable, agreed-upon, and more sustainable future. Do et al. (2021, this issue) applied it as part of participatory land-use planning for multiple ecosystem services in Vietnam, Best et al. (2021, this issue) to enhance inclusive landscape governance in the upper Suriname River Basin, Shantiko et al. (2021, this issue) to deliberate in local multi-stakeholder forums on plausible future land management scenarios for inclusive land-use planning in Indonesia, and Asubonteng et al. (2021, this issue) to engage farmers and institutional actors in deliberations on the spatial dynamics in a mixed cocoa-oil palm landscape in Ghana. Scenario building is a method to mobilize actors around problems that require a long-term vision and may encompass both exploratory and backcasting scenarios (Kok et al. 2011). Most papers in this special issue report on pilots that combined the two. Exploratory scenarios are used to raise awareness of the drivers and consequences of landscape change (a.o. for ecosystem services and carbon emissions) and define what Sayer et al. (2013) refer to as 'common concern entry points' for implementing landscape approaches. Backcasting scenarios are suitable for multistakeholder discussions on the steps needed to achieve desirable futures. The visual features of scenario buildingparticularly when combined with participatory mapping (Asubonteng et al. 2021, this issue) or 3D modeling and a Trade-Off! Game (Best et al. 2021, this issue)—make them attractive and low-threshold tools for people with low literacy. This offers the potential to catalyze marginalized actors' engagement in land-use decisions and enhance their negotiation power (Asubonteng et al. 2021; Do et al. 2021, this issue).

However, several authors observe the difficulty in translating spatial concepts into local languages and the cognitive structures needed to create a shared understanding (Asubonteng et al. 2021; Shantiko et al. 2021, this issue). Participatory scenario building may also be time-consuming, challenging participants' continuous engagement and focus (Asubonteng et al. 2021; Shantiko et al. 2021, this issue). As with other pilots in (action) research, the sustainability of multi-stakeholder initiatives is another serious limitation (see also van Ewijk and Ros-Tonen 2021). In the words of Shantiko et al. (2021, this issue), 'A crucial question is how to systematize what is usually a 'one-shot' process and turn it into a regular, institutionalized practice in land-use planning'. Applying these tools as a continual process outside research settings require funding, political will, and capacity to apply, which are generally missing in developing contexts (Asubonteng et al. 2021, this issue), creating uncertainty about future political commitment and funding (Do et al. 2021, this issue). Last but not least, power imbalances and distrust among actors may hinder reaching consensus or, worse, result in ignoring the voice of the most marginalized people in final decision-making (Best et al. 2021; Shantiko et al. 2021, this issue). Specifically, the 


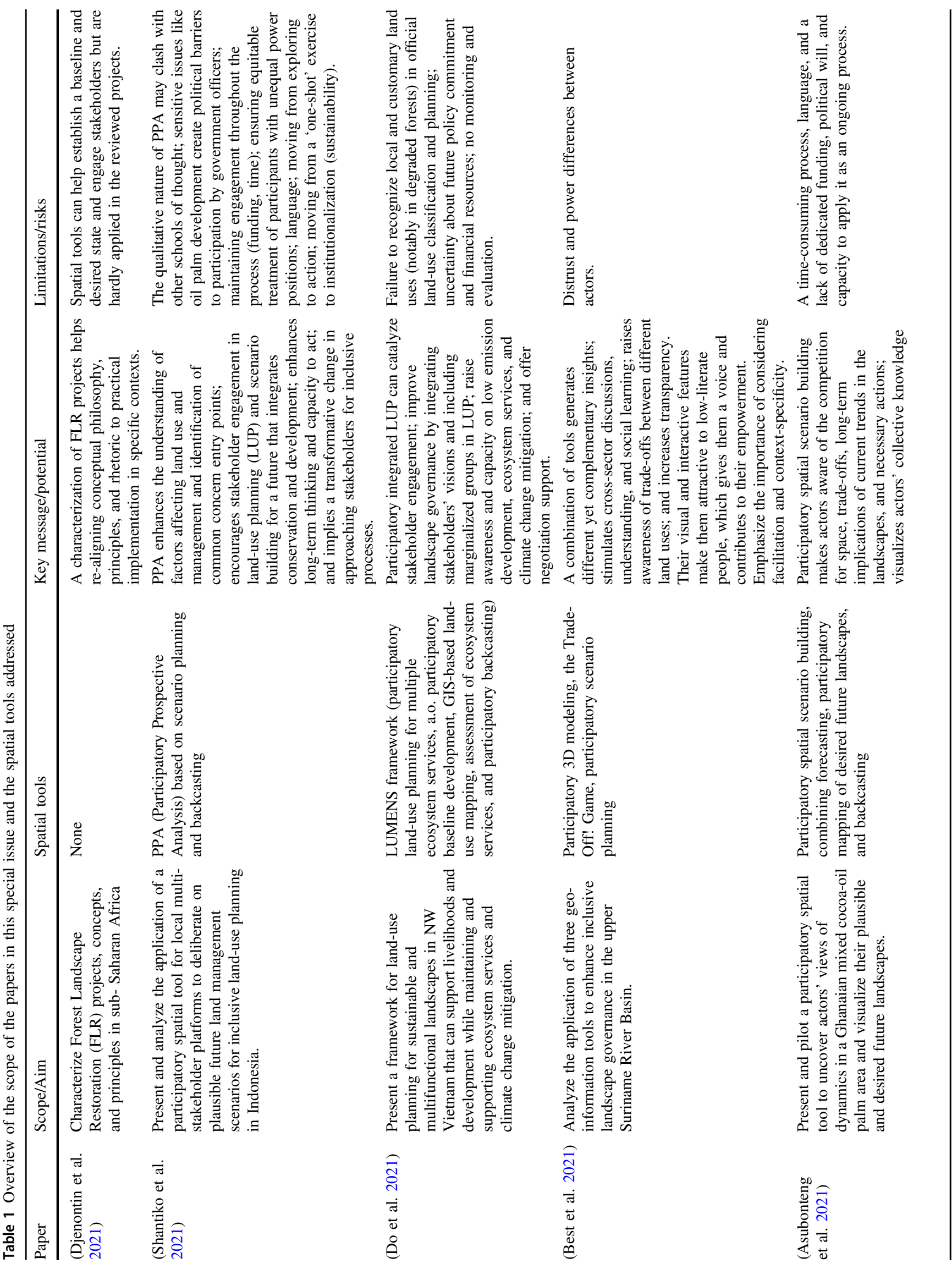




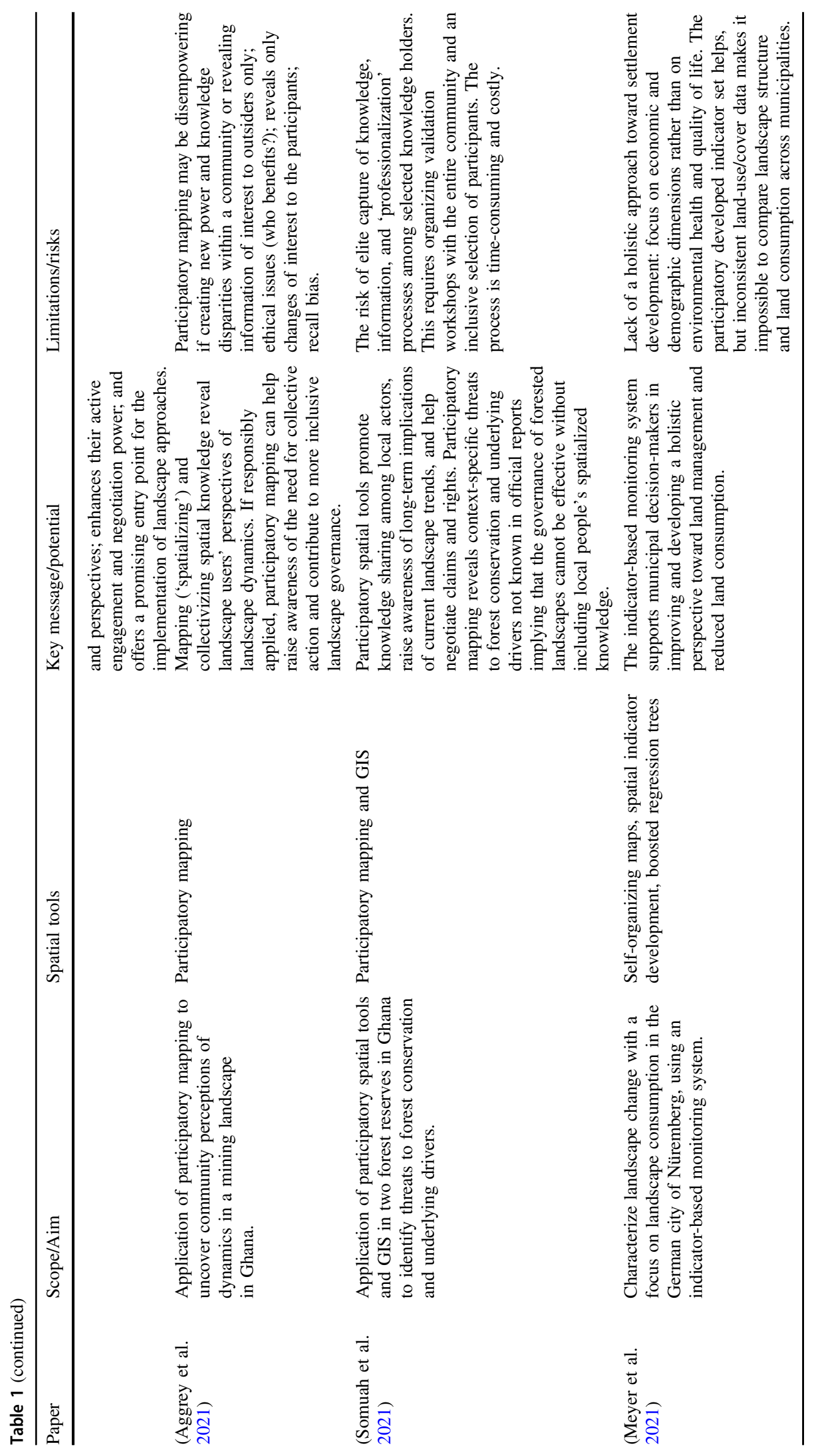


failure to recognize customary tenure and traditional practices has been highlighted in this regard (Do et al. 2021, this issue), whereas such recognition is key to inclusive landscape governance (Rantala et al. 2011; McCall 2016).

The two studies reporting on participatory mapping in Ghana uncover community perceptions of dynamics in a landscape where mining is expanding (Aggrey et al. 2021, this issue) and of threats to forest conservation and underlying drivers (Somuah et al. 2021, this issue). Both argue that local people's spatialized knowledge is key to identifying drivers of landscape change and hence landscape governance. Like scenario building, participatory mapping ('spatializing local knowledge') helps collectivize local knowledge and create awareness of the need for collective action while revealing community perspectives of landscape dynamics. However, both papers warn that participatory mapping may disempower some community members if it creates new power disparities (Aggrey et al. 2021) based on elite capture of knowledge, information, and 'professionalization' processes (Somuah et al. 2021, this issue; see also Bauer 2009; Lund 2015; Verplanke et al. 2016). Careful selection of participants and considering ethics (who decides what will be put on the maps and by whom, who benefits from their use, and who owns the map?) are essential to realizing the empowering effect of participatory mapping (Rambaldi 2005; Chambers 2006; Rambaldi et al. 2006). Somuah et al. (2021 this issue) note that, in practice, local and indigenous knowledge are hardly taken into account in the governance of forested landscapes and that participatory mapping (and scenario building, for that matter) can play a crucial role. In this regard, Shantiko et al. (2021, this issue) point to fundamental ontological and epistemological differences between local knowledge holders and policymakers. Policymakers may not consider qualitative and participatory scenarios and maps a valid basis for policymaking, as they represent worldviews and ideas about knowledge that differ from theirs. Best et al. (2021, this issue) argue that 3D modeling can overcome such epistemological barriers between local communities, government officers, and researchers because the threedimensional visualization makes the landscape 'legible' to stakeholders with different educational backgrounds.

The paper by Meyer et al. (2021, this issue) takes us to a peri-urban setting in Germany. The authors used a participatorily developed indicator set to describe landscapes based on recent changes in them. By characterizing landscapes based on changes in composition and usee.g., identifying 'booming residential' areas or more 'moderate areas' - the authors aim to inform decisionmakers on changes in land claims and the potential policies needed to guide the area toward more sustainable development (e.g., reducing the loss of agricultural land). Their paper clarifies that quantitative, data-driven approaches require consistent data across years and municipalities to draw meaningful conclusions on land consumption in settlement development.

The papers in this special issue collectively show how participatory and participatorily used spatial tools can help achieve inclusive decision-making and landscape governance. By mobilizing stakeholders and stimulating their active engagement, these tools potentially help raise awareness of the consequences of spatial landscape dynamics, give voice to marginalized actors, reconcile diverging interests, and enhance consensus on the necessary steps to curb destructive scenarios toward more sustainable futures. However, several limitations were observed that pose challenges to the inclusivity of the process. Therefore, we call on users and facilitators of participatory spatial processes to recognize the challenges, reflect on them, and further research the scope, openness, and ethics of using spatial tools.

Acknowledgements The guest editors thank the contributing authors for their insights, the reviewers for their constructive comments that helped improve the papers, and the editorial staff of Environmental Management for their encouragement and support.

\section{Compliance with ethical standards}

Conflict of interest The authors declare no competing interests.

Publisher's note Springer Nature remains neutral with regard to jurisdictional claims in published maps and institutional affiliations.

\section{References}

Aggrey JJ, Ros-Tonen MAF, Asubonteng KO (2021, this issue) Using participatory spatial tools to unravel community perceptions of land-use dynamics in a mine-expanding landscape in Ghana. Environ Manag 68. https://doi.org/10.1007/s00267021-01494-7

Asubonteng KO, Ros-Tonen MAF, Baud ISA, Pfeffer K (2021, this issue) Envisioning the future of mosaic landscapes: actor perceptions in a mixed cocoa-oil palm area in Ghana. Environ Manag 68. https://doi.org/10.1007/s00267-020-01368-4

Bauer K (2009) On the politics and the possibilities of participatory mapping and GIS: Using spatial technologies to study common property and land use change among pastoralists in Central Tibet. Cult Geogr 16:229-252. https://doi.org/10.1177/ 1474474008101518

Best L, Fung-Loy K, Ilahibaks N, et al. (2021, this issue) Toward inclusive landscape governance in contested landscapes: exploring the contribution of participatory tools in the Upper Suriname River Basin. Environ Manag 68. https://doi.org/10.1007/s00267021-01504-8

Chambers R (2006) Participatory mapping and geographic information systems: whose map? Who is empowered and who disempowered? Who gains and who loses? Electron J Inf Syst Dev Ctries 25:1-11. https://doi.org/10.1002/j.1681-4835.2006. tb00163.x 
Djenontin INS, Zulu LC, Etongo D (2021, this issue) Ultimately, what is forest landscape restoration in practice? Embodiments in subSaharan Africa and implications for future design. Environ Manag 68. https://doi.org/10.1007/s00267-020-01360-y

Do TH, Vu TP, Catacutan D, Nguyen VT (2021, this issue) Governing landscapes for ecosystem services: a participatory land-use scenario development in the Northwest Montane Region of Vietnam. Environ Manag 68. https://doi.org/10.1007/s00267-020-01378-2

Kok K, van Vliet MM, Bärlund IL et al. (2011) Combining participative backcasting and exploratory scenario development: experiences from the SCENES project. Technol Forecast Soc Change 78:835-851. https://doi.org/10.1016/j.techfore.2011.01.004

Lund JF (2015) Paradoxes of participation: the logic of professionalization in participatory forestry. Policy Econ 60:1-6. https://doi. org/10.1016/j.forpol.2015.07.009

McCall MK (2016) Beyond "landscape" in REDD+: the imperative for "territory". World Dev 85:58-72. https://doi.org/10.1016/j. worlddev.2016.05.001

McCall MK, Dunn CE (2012) Geo-information tools for participatory spatial planning: fulfilling the criteria for "good" governance? Geoforum 43:81-94. https://doi.org/10.1016/j.geoforum.2011.07.007

Meyer MA, Lehmann I, Seibert O, Früh-Müller A (2021, this issue) Spatial indicators to monitor land consumption for local governance in southern Germany. Environ Manag 68. https://doi.org/ 10.1007/s00267-021-01460-3

Rambaldi G (2005) Who owns the map legend? URISA J 17:5-13

Rambaldi G, Chambers R, McCall MK, Fox J (2006) Practical ethics for PGIS practitioners, facilitators, technology intermediaries and researchers. In: Mapping for Change: Practice, Technologies and Communication, Participat. International Institute for Environment and Development, London, p 106-113

Rantala S, Lyimo E, Powell B, et al. (2011) Challenges and opportunities for collaborative landscape governance in the East
Usambara Mountains, Tanzania, ICRAF Work. CIFOR and ICRAF, Bogor

Ros-Tonen MAF, Reed J, Sunderland T (2018) From synergy to complexity: the trend toward integrated value chain and landscape governance. Environ Manag 62:1-14. https://doi.org/10. 1007/s00267-018-1055-0

Ros-Tonen MAF, Willemen L, McCall MK (2021, this issue) Spatial tools for integrated and inclusive landscape governance: potential and limitations. Environ Manag 68

Sayer J, Sunderland T, Ghazoul J, et al. (2013) Ten principles for a landscape approach to reconciling agriculture, conservation, and other competing land uses. P Natl Acad Sci USA 110:8349-8356. https://doi.org/10.1073/pnas.1210595110

Shantiko R, Bourgeois R, Laumonier Y (2021, this issue) Land-use decisions in complex commons: engaging multiple stakeholders through foresight and scenario building in Indonesia. Environ Manag 68. https://doi.org/10.1007/s00267-021-01470-1

Somuah DP, Ros-Tonen MAF, Baud ISA (2021, this issue) Local spatialized knowledge of threats to forest conservation in Ghana's high forest zone. Environ Manag 68. https://doi.org/10.1007/ s00267-021-01455-0

van Ewijk E, Ros-Tonen MAF (2021) The fruits of knowledge cocreation in agriculture and food-related multi-stakeholder platforms in sub-Saharan Africa - A systematic literature review. Agric Syst 186: https://doi.org/10.1016/j.agsy.2020. 102949

Verplanke J, McCall MK, Uberhuaga C et al. (2016) A shared perspective for PGIS and VGI. Cartogr J 53:308-317. https://doi. org/10.1080/00087041.2016.1227552

Willemen L, Kozar R, Desalegn A, Buck LE (2014) Spatial Planning and Monitoring of Landscape Interventions: Maps to Link People with their Landscapes: A User's Guide. EcoAgriculture and Partners, Washington DC 